\title{
PENGELOLAAN KEUANGAN KELUARGA DAN PENGENALAN DASAR-DASAR INVESTASI MENUJU KELUARGA MANDIRI BAGI IBU-IBU MAJELIS TAKLIM AL AULADIYAH, TANGERANG SELATAN
}

\author{
Endah Finatariani, Setianingsih, Anisa, Tsarina Zenabia, Tubagus Arya \\ Abdurachman \\ Universitas Pamulang \\ Email: dosen02502@unpam.ac.id
}

\begin{abstract}
Pengabdian Kepada Masyarakat (PKM) that it calls as Community Service Activities was held from 6-8 July 2020 is a form to fulfilling the obligations of the higher education of Tri Dharma on Pamulang University. The purpose of this PKM are to Introduce of Fundamental Investment and Financial Management Towards Independent Family For Majelis Taklim Al Auladiyah in Tangerang Selatan.Financial management for family is needed so therefor all family needs such as foods, cloths, shelter, school fee or desire to buy a new motorbike/car can be fullfiled. First things first are getting to know your financial condition, and determine you needs not to wants, and choose top priority, family has to preparing household budget for current and future needs, avoids unnecessary desires. One of the stages of financial family planning is preparing a household budget so as to prevent financial failure in the household. The end result or output of this activity is to increase knowledge of the importance of understanding, financial arrangements, improve family welfare so as to avoid dependence on borrowing money from creditors.
\end{abstract}

Keywords: Financial Management, Family Needs, Preparing Bugdet

\begin{abstract}
Abstrak
Kegiatan pengabdian Kepada Masyarakat yang telah berlangsung dari tanggal 6-8 July 2020 adalah untuk melaksanakan salah satu Tri Darma Perguruan Tinggi pada Universitas Pamulang dimana para dosen beraktifitas. Tujuan dari kegiatan PKM adalah untuk memperkenalkan Dasar-Dasar Investasi dan Manajemen Keuangan Menuju Keluarga Mandiri Pada Ibu-Ibu Majelis Taklim Al Auladiyah, Tangerang Selatan. Perencanaan keuangan keluarga dibutuhkan agar tujuan pengelolaan keuangan keluarga dapat tercapai secara efektif, efisien dan bermanfaat. Hal pertama yang harus difahami adalah kenali kondisi keuangan, tentukan kebutuhan utama bukan keinginan, tentukan prioritas dari kebutuhankebutuhan hindari keinginan yang tidak perlu. Salah satu tahapan
\end{abstract}


perencanaan dalam keluarga adalah menyusun anggaran rumah tangga sehingga mencegah kegagalan keuangan dalam rumah tangga. Hasil akhir atau luaran dari kegiatan ini adalah meningkatkan pengetahuan pentingnya pemahaman, pengaturan keuangan, meningkatkan kesejahteraan keluarga sehingga terhindar dari ketergantungan meminjam uang pada kreditur.

Kata Kunci: Perencanaan Keuangan, Kebutuhan Keluarga, Perencanaan Anggaran

\section{A. PENDAHULUAN}

Penghasilan perlu dikelola agar dapat memenuhi kebutuhan saat ini dan juga kebutuhan di masa depan. Kebutuhan saat ini terdiri atas pengeluaran- pengeluaran yang dikeluarkan saat ini, sedangkan kebutuhan di masa depan terdiri atas pengeluaran-pengeluaran di masa mendatang. Setiap manusia memiliki risiko, risiko tersebut dapat mengganggu perolehan penghasilan saat ini dan di masa depan. Oleh karena itu perencanaan keuangan perlu dilakukan secepatnya agar kebutuhan di saat ini dan kebutuhan masa depan tetap dapat terpenuhi.

Menurut Ahmad Gozali (2009) kiat dan tips rahasia sukses dalam mengatur keuangan keluarganya dapat ditempuh dengan langkah-langkah sebagai berikut, yaitu: Utamakan yang utama maksudnya hal ini terkait dengan kewajiban, jika keluarga memiliki hutang/ pinjaman maka terlebih dahulu adalah menyisihkan penghasilan untuk membayar hutang atau pinjaman; selanjutnya yang dilakukan adalah berzakat atau memberikan sumbangan keagamaan, sebagai salah satu bukti rasa syukur kita kepada Allah SWT, Dialah yang telah memberikan karunia rezeki kepada kita semua, sehingga kita bisa melakukan aktivitas ekonomi keseharian dengan lancar tanpa kekurangan, dengan berzakat akan semakin menambah karunia dan rezeki yang berlimpah kepada kita; yang paling penting adalah menyisihkan minimal 10\% penghasilan untuk ditabung/investasi; kemudian ketika semua langkah-langkah tersebut diatas terpenuhi maka sisa penghasilan dapat digunakan untuk keperluan rutin harian seperti belanja isi dapur, makan, lauk-pauk, asuransi, sekolah anak, rekreasi, beli baju dan sebagainya.

Didalam buku Perencanaan Keuangan yang dikeluarkan oleh Otoritas Jasa Keuangan (OJK) dijelaskan pula bagaimana cara merencanakan keuangan yang baik, Berikut langkahlangkah yang diperlukan untuk merencanakan keuangan:

1. Kenali Kondisi Keuangan

2. Tentukan Keinginan

3. Tentukan Keinginan Utama

Kita tidak bisa memenuhi seluruh keinginan tersebut karena adanya keterbatasan. Salah satu keterbatasan yang dimiliki adalah kemampuan keuangan. Oleh karenanya kita perlu membuat urutan keinginan mana yang harus didahulukan.

Kesadaran untuk berinvestasi sangat dibutuhkan, melalui edukasi berinvestasi masyarakat bukan hanya dapat merencanakan keuangan keluarga tapi juga mampu mengelola dengan baik. Salah satu tahapan dalam perencanaan keuangan yang cukup penting adalah penyusunan anggaran rumah tangga, karena ditahap ini merupakan inti mengelola uang yang kita peroleh untuk mencukupi kebutuhan saat ini dan kebutuhan di masa depan. Anggaran yang sehat adalah ketika jumlah pemasukan sama atau lebih besar dari pada pengeluaran, jangan sampai pengeluaran kita lebih besar dari pada pemasukan kita yang sehingga akan menyebabkan kondisi keuangan menjadi defisit. 
Pada era digital saat ini investor dalam hal ini keluarga dapat dengan mudah memilih instrumen investasinya melalui aplikasi ataupun platform investasi, dengan modal kecil sekali pun. Namun, tetap harus memiliki sikap kehati-hatian dalam memilih instrumen dan platform yang tepat untuk berinvestasi.

Tujuan dan target yang ingin dicapai dalam kegiatan pengabdian kepada masyarakat ini adalah pelaksanaan perencanaan keuangan rumah tangga sehingga dapat mencegah kegagalan keuangan dalam rumah tangga. Luaran yang dihasilkan adalah menumbuhkan pengelolaan keuangan yang baik dalam rumah tangga sehingga terhindar dari ketergantungan dari berhutang atau meminjam dari lembaga pembiayaan.

\section{B. METODE PELAKSANAAN KEGIATAN}

Tujuan pelaksanaan dari kegiatan PKM ini adalah (a) Membantu ibu-ibu majlis taklim dalam melakukan pengelolaan keuangan keluarga dengan baik. (b) Memperkenalkan pemahaman dasar-dasar investasi kepada ibu-ibu majlis taklim. (c) Mendorong ibu-ibu majlis taklim untuk memulai berinvestasi secara rutin. (d) Mengajak masyarakat untuk mengimplementasikan pengetahuan yang didapat, dengan cara berinvestasi di sektor keuangan guna mempersiapkan kebutuhan keuangan di masa mendatang.

Metode kegiatan yang digunakan adalah Metode Ceramah dimana peserta akan diberikan pemahaman mengenai gambaran umum pentingnya perencanan keuangan yang baik, bagaimana cara membuat perencanaan dan pengelolaan keuangan dengan metode yang sederhana, mudah dipahami dan mudah diterapkan, sehingga dapat diaplikasikan didalam keuangan keluarga, serta memberikan pengetahuan mengenai dasar-dasar investasi. Metode Tutorial, peserta diberikan beberapa contoh mengenai pengelolaan keuangan keluarga secara manual dan dengan menggunakan aplikasi yang berada didalam smartphone. Metode Diskusi, dimana merupaka sesi terakhir pelatihan teknis manajemen kas rumah tangga yaitu diberikan alokasi waktu untuk sharing dan diskusi terkait kondisi keuangan rumah tangga dan kendala yang sering dialami oleh peserta.

Permasalahan dan kondisi ekonomi masing-masing keluarga berbeda, sehingga perlu ditelaah dan ditindaklanjuti pengelolaan keuangannya dengan penyesuaian dari kondisi keuangan masing - masing. Tahapan persiapan yang dilakukan yaitu:

1. Melakukan studi pustaka tentang berbagai informasi berkaitan pengelolaan keuangan keluarga dan dasar-dasar investasi.

2. Melakukan persiapan alat dan materi yang akan diberikan kepada peserta untuk mempermudah mereka dalam menerima informasi.

3. Menentukan waktu pelaksanaan dan lamanya kegiatan pengabdian bersama-sama dengan tim pelaksana.

Obyek penelitian dari kegiatan pengabdian kepada masyarakat, yaitu ibu-ibu Majlis Taklim Al Auladiyah Kelurahan Bakti Jaya, Kecamatan Setu, Kota Tangerang Selatan. Kegiatan dilakukan untuk memberikan penyuluhan kepada ibu-ibu majlis taklim yang notabene adalah ibu rumah tangga dalam mengelola keuangan dan pengenalan dasar-dasar investasi, bagaimana berinvestasi secara cerdas dan aman dengan memanfaatan sumber daya terbatas yang dimiliki dan mengelolanya dengan optimal. Kegiatan penyuluhan ini diikuti kurang lebih 35 peserta yang terdiri ibu-ibu majlis taklim, pengurus masjid dan perwakilan mahasiswa serta panitia pelaksana yang merupakan dosen Universitas Pamulang. 


\section{HASIL DAN PEMBAHASAN}

\section{Tahap Persiapan}

Melihat kondisi geografis Kelurahan Bakti Jaya yang berdekatan dengan perumahan kelas menengah, didukung akses jalan raya dan dekat dengan stasiun kereta api commuter line yang relatif dekat ke pusat-pusat berbelanjaan, masyarakat membutuhkan kesadaran akan perlunya hidup hemat, membuat skala prioritas dan memanfaatkan dana lebih belanja untuk berinvestasi, mengelola keuangan sebaik mungkin dalam rangka perencanaan keuangan dimasa mendatang, seperti rencana pendidikan anak, pernikahan, renovasi rumah, membeli kendaraan dan sebaginya..

\section{Tahap Pelaksanaan Pengabdian Kepada Masyarakat}

Kegiatan PKM dilakukan di dalam Mesjid Al Auladiyah, dan dilakukan tatap muka serta membuka forum diskusi kepada ibu-ibu Majelis Taklim,

Pelaksanaan Pengabdian Kepada Masyarakat di Lembaga Pemberdayaan Masyarakat pada tanggal 6-8 July 2020. Kegiatan dilaksanakan di Mesjid Al Auladiyah Kelurahan Bakti Jaya, Kecamatan Setu, Kota Tangerang Selatan. Kegiatan ini terlaksana atas kerjasama para dosen dari program Studi Akuntansi dan Manajemen Universitas Pamulang dengan ibu-ibu Majelis Taklim Al-Auladiyah. Dengan tema "Pengelolaan Keuangan Keluarg dan Pengenalan dasar-dasar Investasi Menuju Keluarga Mandiri bagi ibu-ibu Majelis Taklim Al Auladiyah"". Kegiatan ini di ketuai oleh Ibu Endah Finatariani dengan narasumber para dosen dari prodi Akuntansi dan Manajemen.

\section{Tahap Pelatihan}

Kegiatan PKM dilakukan di dalam Mesjid Al Auladiyah, dan dilakukan tatap muka serta membuka forum diskusi kepada ibu-ibu Majelis Taklim, Pemateri memberikan tips dasar kepada peserta penyuluhan untuk dapat mengelola keuangan keluarga dengan lebih baik, sebagai berikut:

a. Mengetahui besaran pendapatan setiap periode (biasanya setiap bulan).

Misalkan penghasilan dari usaha dagang adalah tidak tetap, maka kita membuat range pendapatan minimal sampai dengan maksimal, dan untuk penerapan prinsip kehati-hatian, sebaiknya kita menggunakan pendapatan rata-rata atau bahkan yang minimal saja sebagai pendapatan tiap bulan. Tetapi tidak menutup kemungkinan pendapatan yang dicatat bisa dengan harian. Pendapatan harian bisa didapatkan dari membagi pendapatan bulanan dengan tiga puluh (30) hari.

b. Skala Prioritas

Menetapkan skala prioritas terhadap kebutuhan-kebutuhan yang ada, dengan cara menentukan pengeluaran mana yang lebih penting dalam waktu dekat. Membeli sesuatu yang benar-benar kita butuhkan dan bukan sekedar kita inginkan. Memberikan pengertian perbedaan antara kebutuhan dan keinginan kepada. Akan lebih baik skala prioritas yang kita buat juga disertai anggaran yang ada. Peserta juga diarahkan untuk jeli memilih penjual yang harga jualnya lebih murah dengan kualitas baik untuk dapat berhematMetode ceramah

c. Mencatat pengeluaran dan pemasukan setiap hari.

Hal ini menyambung dari tips poin pertama, bahwa selain mencatat berapa pendapatan yang kita terima, akan lebih baik jika kita mengetahui berapa pengeluaran kita setiap hari. Sebaiknya pengeluaran tiap hari dibuatkan anggaran, ada maksimal pengeluaran yang tidak boleh dilampaui. Selalu berusaha agar pendapatan perhari tidak lebih kecil dari 
pengeluaran, sehingga ada sisa lebih harian yang bisa kita tabung dan nantinya dapat dipergunakan untuk investasiMetode tanya jawab.

d. Evaluasi.

Evaluasi kepada hasil pembukuan sederhana akan memberikan pengetahuan di sisi mana pengeluaran-pengeluaran yang masih dapat dihemat, dan pada sisi pendapatan dapat menemukan alternatif tambahan penghasilan yaitu dengan berinvestasi. Investasi merupakan pengorbanan yang dilakukan pada saat sekarang dengan tujuan untuk mendapatkan manfaat yang lebih besar di masa yang akan datang. (Putri, 2017). Pilihan investasi yang disarankan kepada peserta penyuluhan adalah dengan cara: menabung konvensional, deposito, membeli emas, ataupun reksadana.

Edukasi terkait investasi sangat dibutuhkan oleh masyarakat. Salah satu tahapan dalam perencanaan keuangan yang cukup penting adalah penyusunan anggaran rumah tangga. Karena ditahap ini merupakan inti mengelola uang yang kita peroleh untuk mencukupi kebutuhan saat ini dan kebutuhan di masa depan. Anggaran yang sehat adalah ketika jumlah pemasukan sama atau lebih besar dari pada pengeluaran, jangan sampai pengeluaran kita lebih besar dari pada pemasukan kita yang akan menyebabkan kondisi keuangan menjadi tidak baik.

Pentingnya memahami dasar-dasar investasi, sangat dibutuhkan sebelum memutuskan untuk berinvestasi. Era digital yang ada saat ini memberikan keleluasaan kepada para investor untuk dapat memulai berinvestasi dengan sangat mudah, bahkan dengan modal kecil sekali pun. Namun, tetap harus memiliki sikap kehati-hatian dalam memilih instrumen dan platform yang tepat untuk berinvestasi.

Merencanakan keuangan pribadi dapat dimulai dengan menyusun anggaran keuangan, mengevaluasi program tabungan atau investasi yang sudah dimiliki. Selanjutnya, bagaimana mendanai pendidikan anak-anak, rencana membeli rumah, membeli mobil, perlu dilihat dampaknya terhadap kondisi finansial. Melalui perencanaan keuangan seseorang/keluarga dapat mengerti bagaimana setiap keputusan keuangan yang dibuat berdampak ke area lain dari keseluruhan situasi keuangan diri dan keluarganya.

Berikut dokumentasi dari kegiatan Pengabdian kepada Masyarakat pada ibu-ibu Majelis Taklim Al Auladiyah, Babakan Setu-Pocis, Tangerang Selatan.

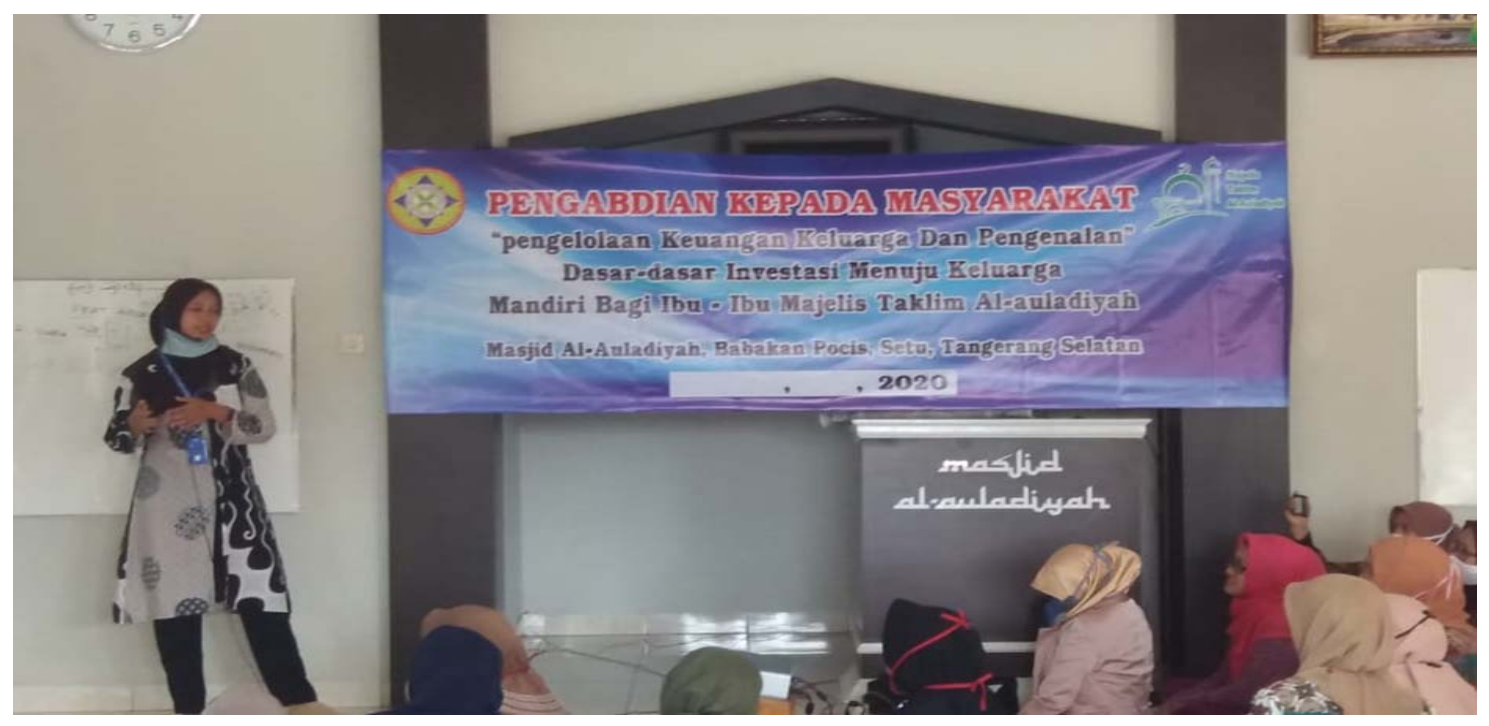

Gambar 1. Diskusi Dengan Peserta saat PKM sedang berlangsung 


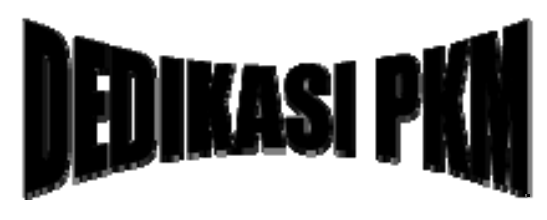

P-ISSN 2716-3652 E-ISSN 2723-1003

DEDIKASI PKM UNPAM

Vol. 1, No. 1, Mei 2020, Hal (132-139)

@Prodi Manajemen Fakultas Ekonomi Universitas Pamulang

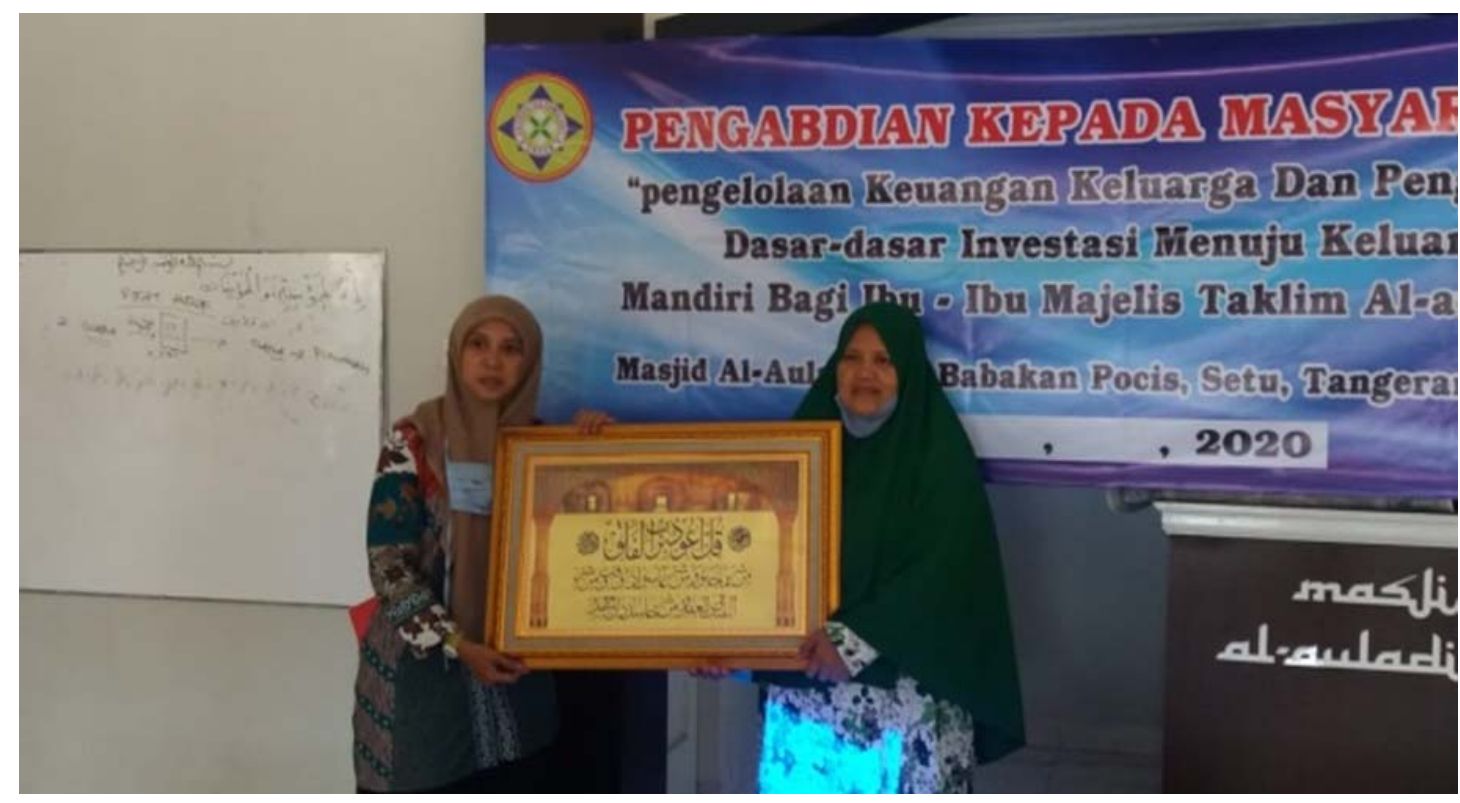

Gambar 2. Foto Penyerahan Plakat Kepada Pimpinan Ketua DKM Al Auladiyah, Baktijaya-Setu, Pocis - Tangerang

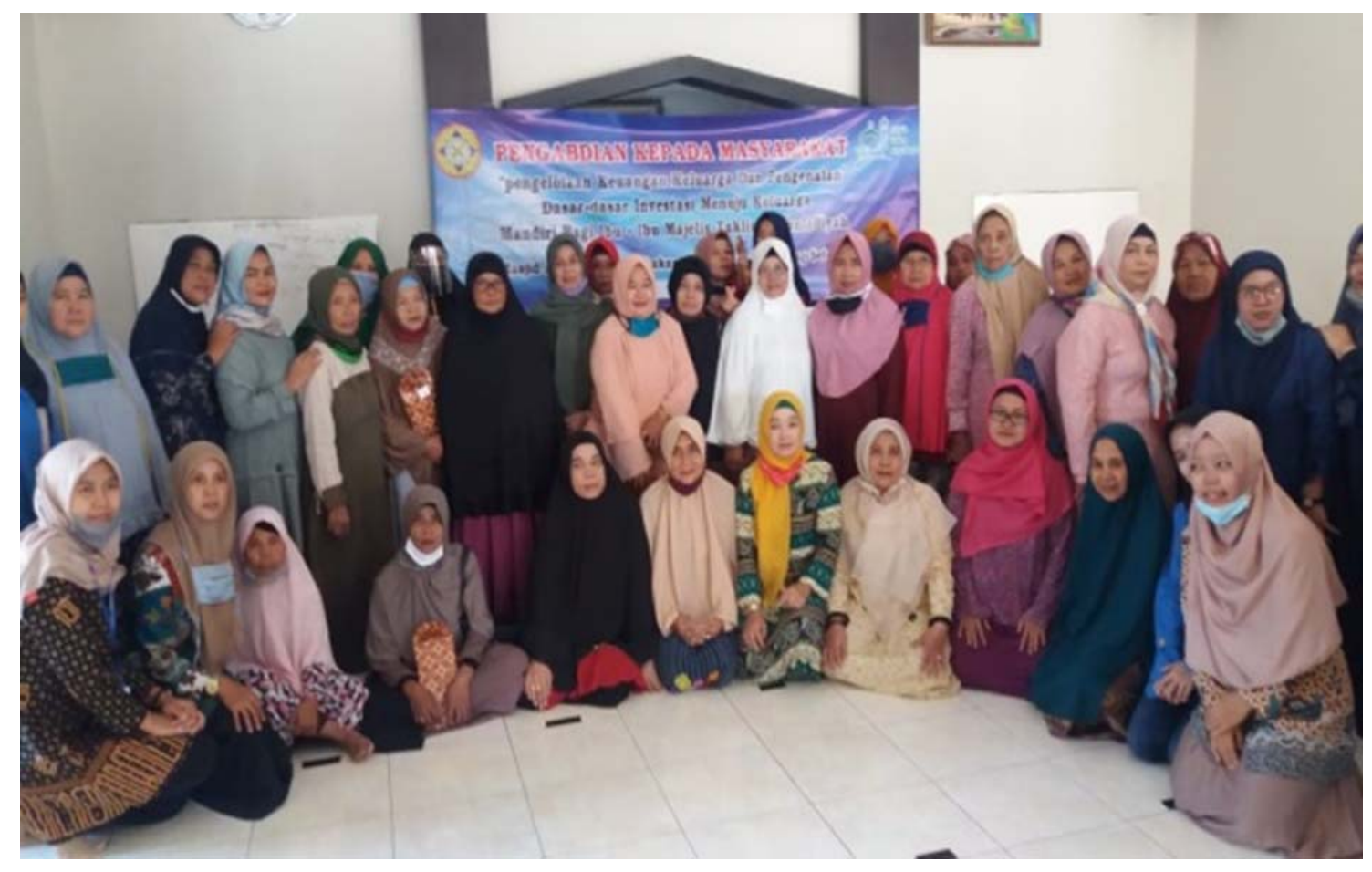

Gambar 3. Foto Tim PKM Bersama Ibu-Ibu Majlis Taklim Al Auladiyah, Bakti Jaya, Setu, Kota Tangerang Selatan 


\section{KESIMPULAN DAN SARAN}

\section{Simpulan}

Dari PKM yang dilakukan menghasilkan kesimpulan bahwa Ibu-Ibu Majlis Taklim Al Auladiyah, Bakti Jaya, Setu, Kota Tangerang Selatan cukup tinggi kesadaran dalam berinvestasinya, hal ini dapat dilihat dari semangat dan pertanyaan-pertanyaan yang diutarakan saat sesi tanya jawab. Namun masih perlu ditumbuhkembangkan lagi agar dapat memilih dan melakukan investasi dengan aman dan hasil yang maksimal untuk dapat mempersiapkan kebutuhan keuangan jangka pendek maupun jangka panjang dan akhirnya mencapai keluarga yang sejahtera.

Selain itu, kebanyakan dari ibu-ibu majlis taklim tersebut juga mempunyai usaha sampingan seperti berjualan, meliliki toko kelontong, berjualan online dengan sistem dropship, berjualan kue dan sebaginya, dalam rangka membantu perekonomian keluarga. Peserta dibimbing bagaimana cara mengelola keuangan, agar sebagian dari hasil usaha sampingannya dapat ditabung atau diinvestasikan untuk kebutuhan keuangan di masa mendatang.

\section{Saran}

PKM yang dilaksanakan merupakan kerjasama dosen prodi S1 Akuntansi Universitas Pamulang dengan pengurus masjid Al Auladiyah, Kelurahan Bakti Jaya, Kecamatan Setu, Kota Tangerang Selatan ini memang dilaksanakan dengan masih banyak kekurangan dan keterbatasan, kami menyarankan untuk PKM selanjutnya, pengenalan dasar-dasar inverstasi ini melibatkan tidak hanya ibu-ibu rumah tangga melainkan juga bapak-bapak sebagai kepala keluarga. Untuk selanjutnya mungkin akan lebih baik untuk melibatkan institusi dari pasar modal secara langsung dalam kegiatan penyuluhan, agar peserta dapat memperoleh gambaran lebih baik lagi mengenai investasi saham maupun reksadana.

\section{Ucapan Terima Kasih}

Dengan memanjatkan puji dan syukur kehadirat Illahi atas terselenggaranya kegiatan PKM di Majelis Taklim Al Auladiyah, tak lupa kami mengucapkan banyak terimakasih kepada seluruh Jemaah Masjid Al Auladiyah serta Bapak H. Basuki Boa, Pimpinan Ketua DKM Al Auladiyah, Baktijaya-Setu, Pocis - Tangerang.

\section{DAFTAR PUSTAKA}

Garlans, S.N. (2014). Motivasi Sebagai Penentu Perencanaan Keuangan. Jurnal Ilmiah Akuntansi dan Bisnis, Vol. 9, No.1:42-48

Muhsin MK, ibid, hal. 6, ia mengutip dari Mohammad Ali Al-Hasyimi, Kepribadian wanita muslimah, hal. 256. ibid, penulis mengutip dari, AM Saefudin, Ada Hari Esok, hal. 3435. Ibid, hal. 7, penulis mengutip dari Dakwah Menjelang Tahun, Jakarta: Koordinator Dakwah Islam, 1986, hal. 65. Muhsin MK, ibid, hal. 9-12. Website:http://uchinfamiliar.blogspot.com/2009/02/pengertian-majelis-taklim-dasarhukum.html, 8 April 2012.

Pangeran, Perminas. 2012. Sikap Keuangan Rumah Tangga Desa pada Aspek Perencanaan Keuangan. JRAK, Vol.8, No.1:35-50 
Putri, N. M. D., \& Rahyuda, H. . (2017). Pengaruh Tingkat Financial Literacy Dan Faktor Sosiodemografi Terhadap Perilaku Keputusan Investasi Individu. E-Jurnal Ekonomi dan Bisnis Universitas Udayana, 6(9).

Setiawan, B. J. J. A. M. (2018). Edukasi Literasi Keuangan Pasar Modal Pengurus PKK Kecamatan Sako Palembang. 2(1).

Silvy, M., \& Yulianti, N. (2013). Sikap pengelola keuangan dan perilaku perencanaan investasi keluarga di Surabaya. Journal of Business \& Banking (JBB), 3(1), 57-68. Tangsel, B. P. S. K. (2019). Kecamatan Setu Dalam Angka 2019.

Solihin, D. (2019), Pengaruh Current Ratio dan Debt to Equtity Ratio Terhadap Return on Asset (ROA) Pada PT. Kalbe Farma Tbk. Jurnal Kreatif, Vol. 7. No. 1.

Subaida, Ida. 2019. Pelatihan Manajemen Kas Rumah Tangga Untuk Mencegah Kegagalan Keuangan Rumah Tangga (Family Financial Distress). INTEGRITAS : JurnalPengabdian Vol 3, No 1. ISSN 2580-7978 (Cetak) ISSN 2615-0794 (Online).

https://sikapiuangmu.ojk.go.id/FrontEnd/images/FileDownload/25_Buku_Perencanaan_Keua ngan.pdf

https://sikapiuangmu.ojk.go.id/FrontEnd/CMS/DetailMateri/17 